\title{
Overexpression of the matrix metalloproteinase 11 gene is a potential biomarker for type 1 endometrial cancer
}

\author{
GABRIELA SOFÍA GÓMEZ-MACÍAS ${ }^{1 *}$, MARÍA LOURDES GARZA-RODRÍGUEZ ${ }^{2 *}$, \\ RAQUEL GARZA-GUAJARDO ${ }^{1 *}$, DANIELA MONSIVÁIS-OVALLE ${ }^{2 *}$, JESÚS ANCER-RODRÍGUEZ $^{1 *}$, \\ HUGO ALBERTO BARRERA-SALDAÑA ${ }^{2 *}$ and ORALIA BARBOZA-QUINTANA ${ }^{1 *}$ \\ Departments of ${ }^{1}$ Pathology and Cytopathology, and ${ }^{2}$ Biochemistry and Molecular Medicine, School of \\ Medicine, Autonomous University of Nuevo León, Monterrey, Nuevo León 64460, Mexico
}

Received January 17, 2017; Accepted September 22, 2017

DOI: $10.3892 / \mathrm{ol} .2018 .8714$

\begin{abstract}
Metalloproteinase matrix 11 (MMP11) is a member of the matrix metalloproteinase family, which are able to degrade extracellular matrix components, and may serve a central function in the enhancement of tumor-induced angiogenesis, cell migration, proliferation, apoptosis and connective tissue degradation. In the present study, MMP11 gene expression was investigated using the reverse transcription-polymerase chain reaction in 68 cases of type I endometrial carcinoma, and all data were analyzed in association with clinical characteristics. Overexpression of MMP11 was demonstrated in $75 \%$, and sub-expression was demonstrated in $25 \%$, of endometrial cancer cases. Sub-expression cases were associated with good histological parameters, including low histological grade (G1 and G2), early pathological stage, and absence of vascular invasion, metastasis and recurrence. In total, $76.4 \%$ of endometrial cancer cases with sub-expression were identified as early stage $1 \mathrm{~A}$ and $\mathrm{B}$; however, $23.6 \%$ of cases were identified as stage 2, with vascular invasion present in $29.4 \%$ of cases. On the other hand, cases which demonstrated overexpression with high ranges ( $>10$ times more than control) were associated with adverse histopathological characteristics, including high grade tumor (G3) and vascular invasion. In conclusion, the increased
\end{abstract}

Correspondence to: Dr Gabriela Sofía Gómez-Macías, Department of Pathology and Cytopathology, School of Medicine, Autonomous University of Nuevo León, Av. Madero Y Gonzalitos S/N, Monterrey, Nuevo León 64460, Mexico

E-mail: bpositivo66@hotmail.com

*Contributed equally

Abbreviations: MMP, matrix metalloproteinase; RT-PCR, reverse transcription-polymerase chain reaction; ECM, extracellular matrix; TIMP, tissue inhibitor of metalloproteinases; ER $\alpha$, estrogen receptor $\alpha$; PR, progesterone receptor

Key words: metalloproteinase matrix 11 gene, type 1 endometrial carcinoma, prognosis, biomarker expression of MMP11 may be used as a prognostic biomarker in patients with type 1 endometrial cancer.

\section{Introduction}

The extracellular matrix (ECM) is a complex meshwork of proteins and carbohydrate polymers, which are secreted, surrounded and anchored by cells of connective tissues. Modulation of the ECM is important in the development and progression of malignancy. Matrix metalloproteinases (MMPs) and the natural tissue inhibitors of metalloproteinases (TIMPs) act synergistically to regulate ECM turnover. Expression of MMPs and TIMPs is involved in several key aspects of tumor growth, invasion and metastasis $(1,2)$. It is hypothesized that MMPs may be associated with the level of invasion and progression in endometrioid-type carcinoma.

MMP11, a member of the MMP family, is able to degrade ECM components, and may serve functions in angiogenesis, cell migration, proliferation, apoptosis and connective tissue degradation. MMP11 is processed intracellularly and is secreted in its active form, thus MMP11 differs from other MMPs that are expressed as proenzymes and processed to active forms through proteolytic cleavage activated extracellularly. This indicates that MMPs may possess a unique function in tumor development and progression; however, MMP11 is unable to degrade major ECM components (3-7).

Endometrial carcinoma (EC) is the most common malignancy of the female genital tract. It is estimated that there are $\sim 200,000$ cases diagnosed worldwide annually, and that $\sim 50,000$ women will succumb to the disease. Despite the recognition of several different histological subtypes of EC, these are commonly explained using a dualistic model, which categorizes carcinomas into two major types: Type I and type II. Type I (endometrioid) comprises the vast majority of EC cases, as well as its histological variants due to the histological similarity with normal endometrial glands. Type I present precursor lesions including glandular hyperplasia and are associated with hyperestrogenism, which is defined by high levels of estrogenic hormones. The mutations are located primarily in phosphatase and tensin homolog, $\beta$ catenin, MutL homolog (MLH)-1 and MLH-6 genes $(8,9)$. Furthermore, patients with type I EC have more favorable prognosis factors 
compared with type II EC (8-12). Several risk factors have been previously associated with type I EC including obesity and the use of estrogen therapies, which are associated with an imbalance between estrogen and progesterone. Combination therapy of oral contraceptives, which are associated with predominant states of progesterone, decreases the risk of EC $(9,13-17)$. Other risk factors include nulliparity, early menarche and late menopause (9). A previous study investigating the expression of MMP1 and MMP2 in EC demonstrated that these biomarkers are associated with poor survival (18). Type II EC are high-grade carcinomas that cannot be graduated and exhibit a poor prognosis; however, these were not included in the present study owing to their behavior, spreading through the serous, having a high stage at the time of presentation and a poor prognostic.

In the present study, the expression levels of MMP11 were measured using the reverse transcription-polymerase chain reaction (RT-PCR) in 68 cases of type I EC and associated with clinical pathological parameters including histological grade (G1-G3), vascular invasion [verified with D240 immunohistochemical (IHC) staining and cluster of differentiation (CD)31], pathological tumor stage ( $\mathrm{pT} 1 \mathrm{a} / \mathrm{lb} / 2 / 3)$, disease recurrence, and mortality. The present study verified expression levels of hormone receptors (estrogen and progesterone receptors) and cell proliferation index using IHC staining, and associated gene expression and pathological parameters with overall prognosis. To the best of our knowledge, there are no previous studies, which have investigated gene association in patients with type I EC. The expression of MMP11 at the protein level using IHC was not performed due to limited sample availability.

\section{Materials and methods}

Ethical approval and consent to participate. The ethics committee of the University Hospital of the Autonomous University of Nuevo León (Monterrey, Mexico) approved the present study. The requirement for consent to participate was not applicable.

Samples and histopathological analysis. In total, 68 cases of type I EC were obtained from the archives of the Pathology Department of the University Hospital of the Autonomous University of Nuevo León during a 5-year period (January 2009 to December 2014). In total, 21 cases (30.8\%) had endometrial tissue adjacent to the tumor, which was included as an internal control for the present study. In total, 20 control cases of proliferative and secretory endometrium were included. EC cases were assessed to verify type, histological grade (G1, well differentiated; G2, moderately differentiated; G3, poorly differentiated) and pT stage (pTla, pT1b, pT2 and pT3a) according to the College of American Pathologists and the International Federation of Gynecology and Obstetrics. In each case, associated clinical pathological data were obtained and analyzed.

IHC analysis. Fixation took place in $10 \%$ neutral buffered formalin (NBF). The most representative tumor areas were selected and $3-\mu \mathrm{m}$-thick sections were produced. The sections were deparaffinized through $310 \mathrm{~min}$ washes in xylene (98.3\%) at room temperature, rehydrated in a descending alcohol series $(100,95,70$ and 50\% ethanol, and finally PBS for $5 \mathrm{~min}$ ) followed by microwave epitope retrieval $[750 \mathrm{~W}$ for $7.5 \mathrm{~min}$ and $500 \mathrm{~W}$ for $5 \mathrm{~min}(\mathrm{x} 4)$ in citrate buffer (pH 6); Thermo Fisher Scientific, Inc., Waltham, MA, USA]. Endogenous peroxidase activity was blocked by incubation with $1 \%$ hydrogen peroxide in methanol for $30 \mathrm{~min}$ before incubation for $1 \mathrm{~h}$ (room temperature) with the polyclonal antibodies against estrogen receptor $\alpha$ (ER $\alpha$; clone 1D5 M704), progesterone receptor (PR; clone PgR 636), Ki67 (clone A047), D240 (clone D2-40) and CD31 (clone JC70A). The sections were stained according to the standard avidin-biotin method from the manufacturer, for $30 \mathrm{~min}$ at room temperature (Dako; Agilent Technologies, Inc., Santa Clara, CA, USA) and counterstained with Harris hematoxylin $(100 \%)$. All antibodies were purchased from Dako; Agilent Technologies, Inc. Tissue microarray slides were evaluated in a standard light microscope (magnification, x100) for immunohistochemical staining.

IHC expression. Positive and negative controls for each marker were included on each slide. Positivity indicated that $>10 \%$ of cells demonstrated nuclear positivity for ER and PR, and an index of high proliferation was considered when $>5 \%$ of cells demonstrated nuclear positivity for Ki67. Furthermore, D240 and CD31 staining was used to confirm the angiolymphatic invasion observed histopathologically. Although no gold standard for identifying angiolymphatic invasion exists, the presence of tumor cells within a vascular space, red blood cells surrounding the tumor cells, identification of endothelial lining of the space, a presence of an elastic lamina surrounding the tumor and tumor cells attached to the vascular wall may be beneficial data for the identification of vascular invasion in the histological sections stained with hematoxylin and eosin (H\&E). The immunohistochemical stains for CD31 and D2-40 were used to assist in the detection of angiolymphatic invasion (Table I).

RNA extraction and quantification. Macrodissections of the most representative areas of EC tumor cases were performed and total RNA was obtained using an All Prep DNA/RNA formalin-fixed paraffin-embedded kit (Qiagen, Inc., Valencia, CA, USA), according to the manufacturer's protocol. RNA was quantified and qualified using a NanoDrop 200 spectrophotometer (Thermo Fisher Scientific, Inc.).

Expression levels of MMPII using RT-PCR. To detect expression levels of MMP11 in endometrial tissues, samples were analyzed using RT-PCR. For relative quantification, RT was performed using SuperScript ${ }^{\circledR}$ VILO $^{\text {TM }}$ cDNA Master Mix (Thermo Fisher Scientific, Inc.) in the Verity Thermal Cycler (Applied Biosystems; Thermo Fisher Scientific, Inc.) using $2 \mu \mathrm{g}$ total RNA for cDNA synthesis for $10 \mathrm{~min}$ at $25^{\circ} \mathrm{C}$ followed by an enzyme inactivation step of $5 \mathrm{~min}$ at $85^{\circ} \mathrm{C}$.

Expression levels were quantified using the $2^{-\Delta \Delta \mathrm{Cq}}$ method and normalized to the internal reference gene $\beta$-actin (19). RT-PCRs were performed using $2 \mathrm{X}$ TaqMan Universal Master Mix with uracil-N-glycosylase (Applied Biosystems; Thermo Fisher Scientific, Inc.) in the StepOnePlus ${ }^{\mathrm{TM}}$ RT-PCR system (Applied Biosystems; Thermo Fisher Scientific, Inc.) with 250 ng cDNA using thermocycling conditions outlined by the manufacturer's protocol, using TaqMan probes ( 40 cycles 
Table I. Clinical and pathological parameters of cases $(n=68)$.

\begin{tabular}{|c|c|c|}
\hline Variable & Frequency & Percentage \\
\hline \multicolumn{3}{|l|}{ Grade } \\
\hline G1 & 3 & 4.4 \\
\hline $\mathrm{G} 2$ & 57 & 83.8 \\
\hline G3 & 8 & 11.7 \\
\hline \multicolumn{3}{|l|}{ Vascular invasion $^{\mathrm{a}}$} \\
\hline Present & 43 & 63.2 \\
\hline Absent & 25 & 36.7 \\
\hline \multicolumn{3}{|l|}{ pT stage } \\
\hline pT1a & 38 & 55.8 \\
\hline pT1b & 19 & 27.9 \\
\hline pT2 & 4 & 5.7 \\
\hline pT3a & 7 & 10.2 \\
\hline \multicolumn{3}{|c|}{ Lymph node dissection } \\
\hline Performed & 37 & $54.4^{\mathrm{b}}$ \\
\hline Not performed & 31 & 45.5 \\
\hline \multicolumn{3}{|l|}{ Adjuvant therapy } \\
\hline Administered & 43 & 63.2 \\
\hline Not administered & 25 & 36.7 \\
\hline \multicolumn{3}{|l|}{ Recurrence } \\
\hline Present & 5 & 7.3 \\
\hline Absent & 63 & 92.6 \\
\hline Mortality & 3 & 4.4 \\
\hline
\end{tabular}

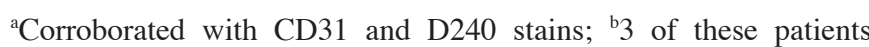
demonstrated lymph node metastasis. pT, pathological tumor.

of $15 \mathrm{sec}$ at $95^{\circ} \mathrm{C}$ with an extension at $60^{\circ} \mathrm{C}$ for $1 \mathrm{~min}$ ). To detect fluorescent signals, the pre-developed TaqMan Gene Expression assay Hs00968295_m1 for MMP11 was used, and Hs99999903_m1 for $\beta$-actin was utilized as an internal control (forward, 5'-GTGGGCCGCTCTAGGCACCAA-3', reverse, 3'-CTCTTTGATGTCACGCACGATTTC-5', belong to Applied Biosystems; Thermo Fisher Scientific, Inc.). RT-PCR was performed in independent replicates. Two biological replicates for each sample were used for RT-PCR analysis and three technical replicates were analyzed for each biological replicate. A value of $>1$ was considered as overexpression, and $<1$ was considered as sub-expression, according to the standard value on control secretory endometrium (the endometrial cycle has two secretory and proliferative phases, which were used as controls). To analyze the gene expression stability, geNORM v3.4 software (Genome Biology, London, UK) was used.

Statistical analysis. An analysis of the possible association between patterns of MMP11 expression and clinical pathological variables including age, histological grade, pathological stage, vascular invasion, recurrence and mortality, as well as expression levels of hormone receptors (ER/PR) and Ki67, were performed using the $\chi^{2}$ test. $\mathrm{P}<0.05$ was considered to indicate a statistically significant difference. Receiver operating characteristic analysis was used to validate the overexpression of MMP11 at a specificity of 0.49 with a confidence interval of $0.33-0.64$, and sensibility of 0.75 with a confidence interval of $0.65-0.85$.

\section{Results}

Clinical-pathological parameters. The mean age of patients with EC was 55 years (range, 33-82 years). Histological grades for type I EC included G2 (83.8\%) followed by G3 (11.7\%) and G1 (4.4\%). Angiolymphatic (vascular) invasion was present in $63.2 \%$ of cases (Table I). Invasion in histological H\&E sections was investigated and analyzed for association with CD31 and D240 staining. No false positives or false negatives were observed (Table I). The majority of patients with angiolymphatic invasion demonstrated overexpression (70.6\%), and presented G2 staging in $87 \%$ of cases and stages pT1b, 2 and $3 \mathrm{a}$ in $>90 \%$ of cases. With regard to the pathological stage, the majority of cases were localized (stage 1A and B; 83.8\%), no patient presented at stage IV. Patients underwent pelvic lymph node dissection in $54 \%$ of cases and $8 \%$ demonstrated lymph node metastases. In total, $63 \%$ of patients with EC received adjuvant therapy (radiotherapy and chemotherapy) and disease recurrence occurred in $7 \%$ of cases, all of which were localized at the vaginal vault level. Within the first 2 years of surgery, 3 patients who had presented at advanced-stage at the time of diagnosis had succumbed to the disease. Clinical pathological data are presented in Table I.

Expression levels of MMP11. MMP11 was overexpressed in $75 \%(n=51)$, and sub-expressed in $25 \%(n=17)$ of EC cases. Levels of overexpression ranged between 1.1- and 600-fold (Fig. 1). Cases with sub-expression were primarily associated with G1 (well-differentiated) followed by G2 (moderately differentiated); however, all G3 (poorly differentiated) cases demonstrated overexpression, and the remainder $\mathrm{G} 2$ cases were overexpressed. In $76.4 \%$ of cases with sub-expression, early pT stages (1A and B) were demonstrated, and $23.6 \%$ presented at stage 2 . The remaining early-stage cases $(23.6 \%), 76.4 \%$ of stage 2 cases and all stage 3 cases were overexpressed. In total, $29.4 \%$ of cases with sub-expression demonstrated vascular invasion. Internal controls with endometrium adjacent to the tumor demonstrated overexpression in $66.6 \%$ with expression levels ranging between 1.1 - and 3.5-fold, and $33.4 \%$ with sub-expression of the gene MMP11 (Fig. 1).

Statistical analysis. No statistically significant association between MMP11 expression and age, nuclear grade, adjuvant therapy, recurrence or mortality was identified. However, pT pathological stage and vascular invasion demonstrated a statistically significant association with gene expression $(\mathrm{P}=0.03$ and 0.01 , respectively; Table II).

IHC expression. The ER $\alpha$ IHC stain was positive in $80.8 \%$ of cases, and associated with histological grades 1 and $2(92.7 \%)$. The PR IHQ stain was expressed in $76.4 \%$ of cases; increased proportions of PR were associated with low histological grades (92.4\%) and early pathological stages $(90.5 \%)$. The rate of cell proliferation determined using immunohistochemical staining with Ki67 was increased in $45(66 \%)$ of cases and decreased in $23(44 \%)$ of cases; $95.6 \%$ of the latter demonstrated low nuclear 


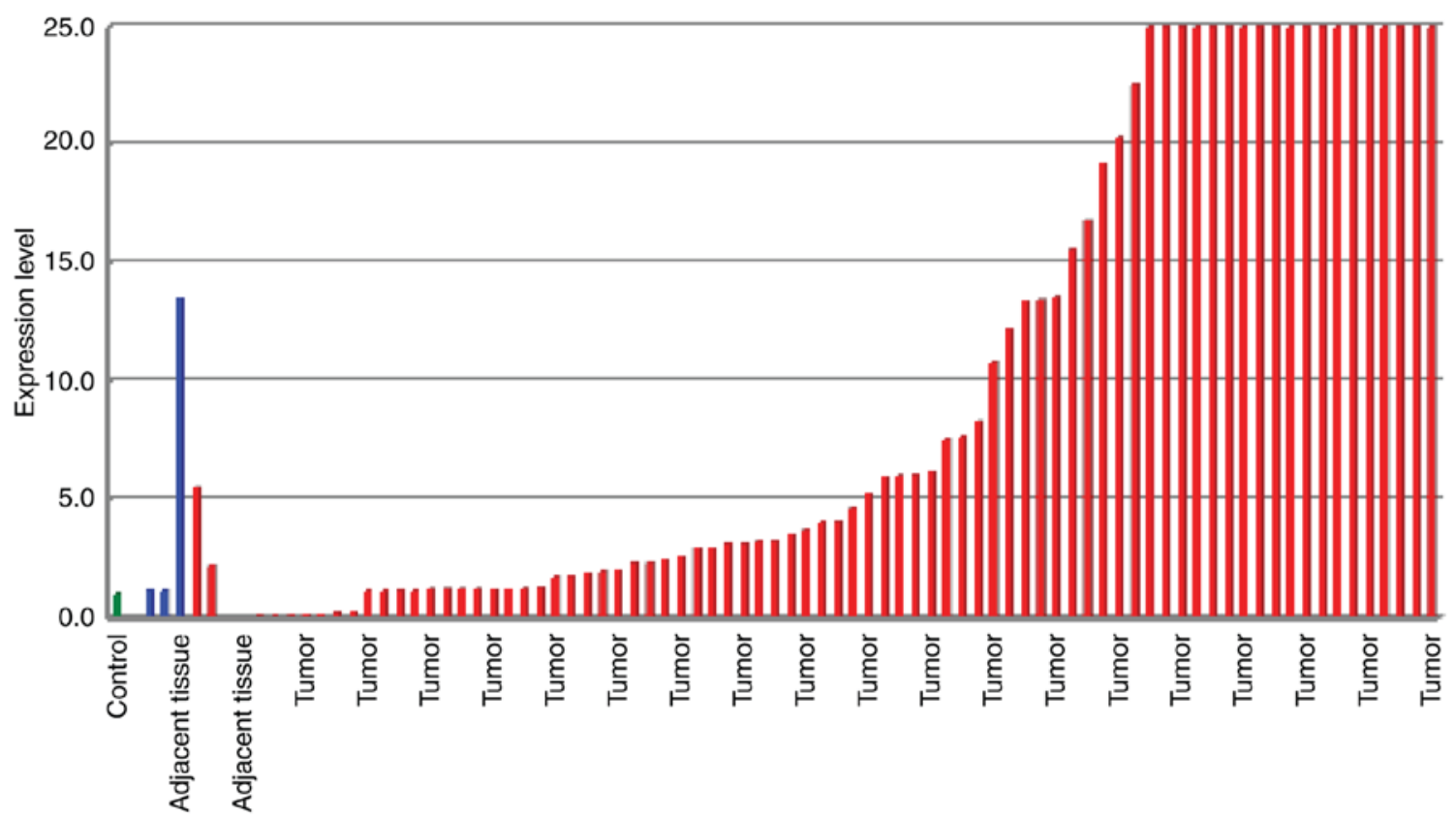

Figure 1. Expression levels of MMP11 gene in EC tumors and adjacent tissues. Values $>1$ were considered as overexpression, ranging between 1.1- and 600-fold. MMP, matrix metalloproteinase.
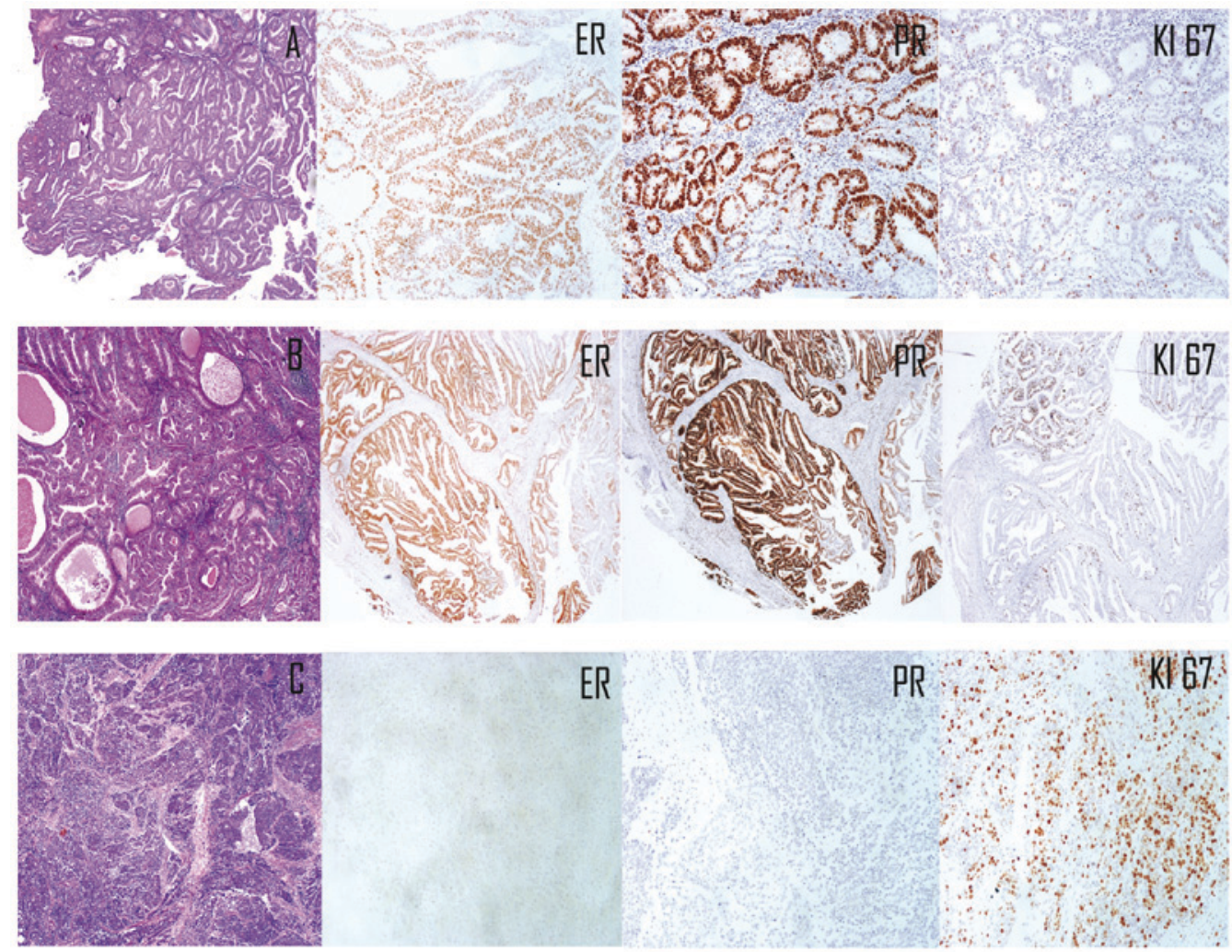

Figure 2. Immunohistochemical staining of EC using H\&E, ER, PR and Ki67 staining. (A) Well-differentiated endometrioid carcinoma (magnification, x100). (B) Moderately differentiated endometrioid carcinoma (magnification, x100). (C) Poorly differentiated endometrioid adenocarcinoma (magnification, x100). $\mathrm{H} \& \mathrm{E}$, hematoxylin and eosin; EC, endometrial carcinoma; ER, estrogen receptor; PR, progesterone receptor.

grades (1 and 2), and all cases presented at stages $1 \mathrm{~A}$ and $\mathrm{A}$ (Fig. 2). Hormone receptors were not statistically significant factors $(\mathrm{P}=0.25$ and 0.20 for $\mathrm{ER}$ and $\mathrm{PR}$, respectively); however, the cell proliferation index of Ki67 was significant $(\mathrm{P}=0.04$; Table II $)$.

\section{Discussion}

The expression of $M M P$ in EC has been previously studied; among these types 1,2, 7 and 9 demonstrated overexpression and were associated with a poor prognosis (19-28).MMP14 has 
Table II. Clinical and pathological parameters, hormone receptors and Ki67 associated with matrix metalloproteinase 11 expression.

\begin{tabular}{lc}
\hline Variable & P-value \\
\hline Age & 0.12 \\
Nuclear grade & 0.13 \\
pT pathological stage & 0.03 \\
Metastatic lymph nodes & 0.21 \\
Angiolymphatic invasion & 0.01 \\
Adjuvant therapy & 0.20 \\
Recurrence & 0.43 \\
Mortality owing to disease & 0.75 \\
a-Estrogen receptors & 0.25 \\
Progesterone receptors & 0.20 \\
Ki67 & 0.04 \\
\hline
\end{tabular}

pT, pathological tumor.

been associated with increased myometrial and lymph node invasion; however, the study was limited to a small number of cases (26). Previous studies regarding carcinomas within the biliary tract, oral cavity, thyroid and colon demonstrated an association between MMP11 overexpression and a poorer prognosis (27-29). In the present study, overexpression of MMP11 ranging between 1.1- and 600-fold normal values was demonstrated and was identified to be associated with adverse histopathological characteristics including high nuclear grade, advanced stages, angiolymphatic invasion, recurrence and mortality; in contrast, cases with sub-expression which represented the total number of cases with well-differentiated and moderately differentiated histological grades presented at an early stage in the disease process.

In the present study, the majority of the cases $(83.8 \%)$ were represented by a moderately differentiated histological grade (G2), and were diagnosed in the early stages pT1a and pT1b (83.7\%), which coincides with results reported in previous literature (30-33). This is a limitation of the present study because of the low percentage of carcinomas that are well and poorly differentiated, as well as a low number of late stages.

Furthermore, previous studies investigating cancer cell lines associated with hormones, including breast, ovarian and prostate carcinoma, demonstrated an association between overexpression of MMPs and increased proliferation and invasion of carcinogenic cells (34). In the present study, the expression of hormone receptors (ER $\alpha$ and PR) was evaluated in cases with type I EC (endometrioid and variants). Cases with an increased percentage of positivity of hormone receptors (ER and PR; $>70 \%$ ) were associated with fewer adverse histopathological features when compared with cases that demonstrated negativity or sub-expression of these receptors.

Previous studies have attempted to identify MMP11 as a potential predictive tumor biomarker in patients with gastric carcinoma; results demonstrated a significant increase in the serum levels in these patients, thus proposing it as a biomarker for diagnosing certain types of carcinomas. The results of the present study suggest that EC may be included, once data are validated, as the results in the present study are in agreement with those of a previous study in terms of progression and prognosis (35).

However, to the best of our knowledge, there have been no previous studies, which associated the cell proliferation index with the expression of MMPs. In the present study, the rate of proliferation was determined using Ki67 staining, in which an increased rate of proliferation was identified to be associated with adverse histopathological parameters, increased levels of MMP11 expression $(\mathrm{P}=0.04)$, vascular invasion and pathological staging. This supports the hypothesis that MMPs are associated with the level of invasion and progression in endometrioid-type carcinoma.

Despite previous evidence demonstrating that MMP11 overexpression is a potential biomarker in this type of neoplasia, a key limitation to the present study is the relative lack of IHC analysis. It is recommended that future studies increase the number of cases and perform MMP11 protein IHC analysis in tissue microarrays to corroborate MMP11 overexpression as a biomarker.

To conclude, the increased MMP11 expression in type I EC is associated with a poor prognosis. Overexpression may be used as a prognostic biomarker in patients with type I EC; however, studies with a larger sample size are required to support this hypothesis.

\section{Acknowledgements}

The authors would like to thank Dr Ricardo Cerda Flores for providing support with statistical analysis. The present study was supported by the Department of Pathology and Cytopathology of the University Hospital of the Autonomous University of Nuevo León (Monterrey, Mexico).

\section{Funding}

No funding was received.

\section{Availability of data and materials}

The datasets used and/or analyzed during the current study are available from the corresponding author on reasonable request.

\section{Authors' contributions}

GSGM, MLGR and DMO were responsible for the conception and design of the study, and the acquisition, analysis and interpretation of data. RGG, JAR, OBQ and HABS made substantial contributions to conception and design and acquisition of data. They were involved in revising it critically for intellectual content and final approval of the version to be published.

\section{Ethics approval and consent to participate}

The present study was approved by the ethics committee of the University Hospital of the Autonomous University of Nuevo León (approval no. AP 14-001). 


\section{Consent for publication}

Not applicable for this manuscript.

\section{Completing interests}

The authors declare that they have no competing interests.

\section{References}

1. Yan C and Boyd DD: Metalloproteinase gene expression. J Cell Physiol 211: 19-26, 2007.

2. Roycik MD, Fang X and Sang OX: A fresh prospect of extracellular hydrolytic enzymes and their substrates. Curr Pharm Des 15: 1295-1308, 2009.

3. Murphy $\mathrm{G}$ and Nagase $\mathrm{H}$ : Progress in matrix metalloproteinase research. Mol Aspects Med 29: 290-308, 2008.

4. Obokata A, Watanabe J, Nishimura Y, Arai T, Kawaguchi M and Kuramoto H: Significance of matrix metalloproteinase-7 [correction of matrix metalloproteinase-2], -11 and tissue inhibitor of metalloproteinase-1 expression in normal, hyperplastic and neoplastic endometrium. Anticancer Res 27: 95-105, 2007.

5. Mueller J, Brebeck B, Schmalfeldt B, Kuhn W, Graeff H and Höfler H: Stromelysin-3 expression in invasive ovarian carcinomas and tumors of low malignant potential. Virchows Arch 437: 618-624, 2000

6. Docherty AJ, Lyons A, Smith BJ, Wright EM, Stephens PE, Harris TJ, Murphy G and Reynolds JJ: Sequence of human tissue inhibitor of metalloproteinase and its identity to erythroidpotentiating activity. Nature 318: 66-69, 1985.

7. Hampton AL and Salamonen LA: Expression of messenger ribonucleic acid encoding matrix metalloproteinases and their tissue inhibitors is related to menstruation. J Endocrinol 141: R1-R3, 1994.

8. Azueta A, Gatius S and Matias-Guiu X: Endometrioid carcinoma of the endometrium: Pathologic and molecular features. Semin Diagn Pathol 27: 226-240, 2010.

9. Felix AS, Weissfeld JL, Stone RA, Bowser R, Chivukula M, Edwards RP and Linkov F: Factors associated with type I and type II endometrial cancer. Cancer Causes Control 21: 1851-1856, 2010.

10. Stoian SC, Simionescu C, Mărgăritescu C, Stepan A and Nurciu M: Endometrial carcinomas: Correlation between ER, PR, Ki67 status and histopathological prognostic parameters. Rom J Morphol Embryol 52: 631-636, 2011.

11. Gottwald L, Kubiak R, Sek P, Piekarski J, Szwalski J, Pasz-Walczak G, Spych M, Suzin J, Tylińskis W and Jeziorski A: The value of $\mathrm{Ki}-67$ antigen expression in tissue microarray method in prediction prognosis of patients with endometrioid endometrial cancer Ginekol Pol 84: 444-449, 2013 (In Polish).

12. Urabe R, Hachisuga T, Kurita T, Kagami S, Kawagoe T, Matsuura $Y$ and Shimajiri S: Prognostic significance of overexpression of p53 in uterine endometrioid adenocarcinomas with an analysis of nuclear grade. J Obstet Gynaecol Res 40: 812-819, 2014

13. Cancer Genome Atlas Research Network; Kandoth C, Schultz N, Cherniack AD, Akbani R, Liu Y, Shen H, Robertson AG, Pashtan I, Shen R, et al: Integrated genomic characterization of endometrial carcinoma. Nature 497: 67-73, 2013

14. McCullough ML, Patel AV, Patel R, Rodriguez C, Feigelson HS, Bandera EV, Gansler T, Thun MJ and Calle EE: Body mass and endometrial cancer risk by hormone replacement therapy and cancer subtype. Cancer Epidemiol Biomarkers Prev 17: 73-79, 2008.

15. Sherman ME, Sturgeon S, Brinton LA, Potischman N, Kurman RJ, Berman ML, Mortel R, Twiggs LB, Barrett RJ, Wilbanks GD, et al: Risk factors and hormone levels in patients with serous and endometrioid uterine carcinomas. Mod Pathol 10: 963-968, 1997

16. Uccella S, Mariani A, Wang AH, Vierkant RA, Robien K, Anderson KE and Cerhan JR: Dietary and supplemental intake of one-carbon nutrients and the risk of type I and type II endometrial cancer: A prospective cohort study. Ann Oncol 22: 2129-2136, 2011.

17. Yang HP, Wentzensen N, Trabert B, Gierach GL, Felix AS, Gunter MJ, Hollenbeck A, Park Y, Sherman ME and Brinton LA: Endometrial cancer risk factors by 2 main histologic subtypes: The NIH-AARP Diet and Health Study. Am J Epidemiol 177: 142-151, 2013.
18. Honkavuori-ToivolaM,SantalaM,SoiniY,Turpeenniemi-Hujanen T and Talvensaari-Mattila A: Combination of strong MMP-2 and weak TIMP-2 immunostainings is a significant prognostic factor in endometrial carcinoma. Dis Markers 35: 261-266, 2013.

19. Guo W, Chen G, Zhu C and Wang H: Expression of matrix metalloproteinase-2, 9 and its tissue inhibitor-1, 2 in endometrial carcinoma. Zhonghua Fu Chan Ke Za Zhi 37: 604-607, 2002 (In Chinese).

20. Karahan N, Güney M, Baspinar S, Oral B, Kapucuoglu N and Mungan T: Expression of gelatinase (MMP-2 and MMP-9) and cyclooxygenase-2 (COX-2) in endometrial carcinoma. Eur J Gynaecol Oncol 28: 184-188, 2007.

21. Honkavuori M, Talvensaari-Mattila A, Soini Y, Turpeenniemi-Hujanen T and Santala M: MMP-2 expression associates with CA 125 and clinical course in endometrial carcinoma. Gynecol Oncol 104: 217-221, 2007.

22. Talvensaari-Mattila A, Santala M, Soini Y and Turpeenniemi-Hujanen T: Prognostic value of matrix etalloproteinase-2 (MMP-2) expression in endometrial endometrioid adenocarcinoma. Anticancer Res 25: 4101-4105, 2005.

23. Graesslin O, Cortez A, Uzan C, Birembaut P, Quereux C and Daraï E: Endometrial tumor invasiveness is related to metalloproteinase 2 and tissue inhibitor of metalloproteinase 2 expressions. Int J Gynecol Cancer 16: 1911-1917, 2006.

24. Graesslin O, Cortez A, Fauvet R, Lorenzato M, Birembaut P and Daraï E: Metalloproteinase-2, -7 and -9 and tissue inhibitor of metalloproteinase- 1 and -2 expression in normal, hyperplastic and neoplastic endometrium: A clinical-pathological correlation study. Ann Oncol 17: 637-645, 2006.

25. Aglund K, Rauvala M, Puistola U, Angström T, Turpeenniemi-Hujanen T, Zackrisson B and Stendahl U: Gelatinases A and B (MMP-2 and MMP-9) in endometrial cancer-MMP-9 correlates to the grade and the stage. Gynecol Oncol 94: 699-704, 2004.

26. Di Nezza LA, Misajon A, Zhang J, Jobling T, Quinn MA, Ostör AG, Nie G, Lopata A and Salamonsen LA: Presence of active gelatinases in endometrial carcinoma and correlation of matrix metalloproteinase expression with increasing tumor grade and invasion. Cancer 94: 1466-1475, 2002.

27. Tongtawee T, Kaewpitoon SJ, Loyd R, Chanvitan S, Leelawat K, Praditpol N, Jujinda S and Kaewpitoon N: High expression of matrix metalloproteinase-11 indicates poor prognosis in human cholangiocarcinoma. Asian Pac J Cancer Prev 16: 3697-3701, 2015.

28. Hsin CH, Chen MK, Tang CH, Lin HP, Chou MY, Lin CW and Yang SF: High level of plasma matrix metalloproteinase-11 is associated with clinic pathological characteristics in patients with oral squamous cell carcinoma. PLoS One 9: e113129, 2014.

29. Xu CJ and Xu F: MMP-11 and VEGF-C expression correlate with clinical features of colorectal adenocarcinoma. Int $\mathrm{J}$ Clin Exp Med 7: 2883-2888, 2014.

30. Sanci M, Güngördük K, Gülseren V, Karadeniz T, Kocaer M, Gungorduk $\mathrm{O}$ and Özdemir İA: MELF pattern for predicting lymph node involvement and survival in grade I-II endometrioid-type endometrial cancer. Int J Gynecol Pathol 37: 17-21, 2018.

31. Mariani A, Dowdy SC, Cliby WA, Gostout BS, Jones MB, Wilson TO and Podratz KC: Prospective assessment of lymphatic dissemination in endometrial cancer: A paradigm shift in surgical staging. Gynecol Oncol 109: 11-18, 2008.

32. Yldirim ME, Karakuş S, Kurtulgan HK, Kılıçgün H, Erşan S and Bakır S: The association of plasminogen activator inhibitor type 1 (PAI-1) Level and PAI-1 4G/5G gene polymorphism with the formation and the grade of endometrial cancer. Biochem Genet 55: 314-321, 2017

33. Roma AA, Rybicki LA, Barbuto D, Euscher E, Djordjevic B, Frauenhoffer E, Kim I, Hong SR, Montiel D, Ali-Fehmi R, et al: Risk factor analysis of recurrence in low-grade endometrial adenocarcinoma. Hum Pathol 46: 1529-1539, 2015.

34. O'Mara TA, Clements JA and Spurdle AB: The use of predictive or prognostic genetic biomarkers in endometrial and other hormone-related cancers: Justification for extensive candidate gene single nucleotide polymorphism studies of the matrix metalloproteinase family and their inhibitors. Cancer Epidemiol Biomarkers Prev 18: 2352-2365, 2009.

35. Yang YH, Deng H, Li WM, Zhang QY, Hu XT, Xiao B, Zhu HH, Geng PL and Lu YY: Identification of matrix metalloproteinase 11 as a predictive tumor marker in serum based on gene expression profiling. Clin Cancer Res 14: 74-81, 2008. 